\title{
INTESTINAL PARASITES IN CHILDREN *
}

\author{
GASTON J. GREIL, B.S., M.D.
}

Pediatrician to St. Margaret's Hospital, Masonic Widows' and Orphans'

Home and West End Dispensary for Children

MONTGOMERY, ALA.

The subject of intestinal parasites in children is one that I believe has not been given the care and attention that it rightly deserves. Generally speaking, only those patients are examined for parasites who come with a definite history referable to the parasites, such as the finding of a segment of tenia in the stools, or when the mother of the patient makes the statement that she believes that her child has worms, do we ask for a specimen and examine or have the stools examined.

That this was true was forcibly brought to my attention by the number of cases that came to me, both in my private practice and in the West End Dispensary, either with the statement by the mother that the child had worms, or with the child complaining of other symptoms not referable to a parasitic disease; yet on routine examination these cases were found to harbor one or more of the different parasites to be mentioned later.

Although the Rockefeller Hookworm Commission had as thoroughly and systematically worked the state by counties as was possible with funds and time available, I determined to study the subject through the children that came under my observation in my clinic, at the Masonic Home, and also through the courtesy of Dr. P. B. Moss, State Pathologist and Bacteriologist, the children under the age of 12 years who came to the State Pasteur Institute to be treated for dog bites.

My observations include all those children who were at the Masonic Home or who came to the clinic or Pasteur Institute, regardless of the nature of their complaints. Some of them, especially the cases from the Home and Pasteur Institute, did not complain of any untoward symptoms whatsoever. In fact, they were perfectly healthy specimens whose parents would never have thought to consult a physician had it not been for the accidental bite of a supposedly rabid dog and their fear of hydrophobia. These observations cover a period from Septem-

* Submitted for publication Aug. 15, 1915.

* Read before the Chattahoochee Valley Medical and Surgical Association, July 14, 1915. 
ber, 1910, to March, 1915, in the Pasteur Institute, and from May, 1914, to April, 1915, in my own dispensary and Masonic Home. (The examinations were made in the State Laboratory by Dr. P. B. Moss or one of his assistants). The total number of children examined being 665,80 of whom were negroes, and all under 12 years of age. Of this number 240 were found to be infected; 425 negative, or 36.1 per cent., of the children were found to harbor one or more of the varieties of parasites as follows:

\begin{tabular}{|c|c|}
\hline $\begin{array}{l}\text { is } \ldots \ldots \ldots \ldots \ldots \ldots \\
\text { is nana } \ldots \ldots \ldots \ldots \ldots\end{array}$ & 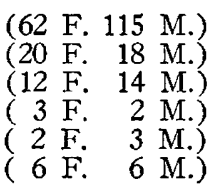 \\
\hline
\end{tabular}

Amoeba coli and Amoeba histolytica will not be considered here.

Of these infections it will be noted that three children of one family had a double infection of Ascaris lumbricoides and Trichocephalus dispar. In one family one child was infected with hookworm and Hymenolepis nana while the second had hookworm only. In the third family one child was infected with Hymenolepis nana and Trichocephalus. In still another, one child was infected with Hymenolepis nana, with both hookworm and Hymenolepis nana in the second.

It is a common occurrence to find whole families infected with hookworm, while in five families Hymenolepis nana was found in two or more members. In many cases it was only possible to examine one child of a family or I believe this number would be largely increased.

It is to be remembered that very few of these patients complained of any untoward symptoms due to the parasites, but as before stated, came to the Pasteur Institute to be treated for dog bites, or to the dispensary for any of the ordinary diseases that usually come to a dispensary or free clinic.

It might be well to mention here that of the patients presenting themselves to the Pasteur Institute 34.5 per cent. were infected. Many of them came from Birmingham, Mobile, Montgomery, Selma and the larger centers of population of the state where hookworm infection is not so common as in the rural districts and medical attention is much easier to obtain, and where had they complained of any symptoms referable to the parasites, they would more than likely have been discovered and treated.

Therefore, the percentage of intestinal parasites in children of the state as a whole may be considered even larger than have been found here.

The large percentage of parasites which apparently give no untoward symptoms might easily lead one to believe that they are of 
little relative importance to the health of the child. That such is not the case $I$ have proved to my own satisfaction by treating several children complaining of abdominal pains, loss of appetite, tired, listless feeling, etc., and giving them a thorough treatment, watching the marked improvement in the general condition and the disappearance of symptoms complained of. Especially was this so in some of the children of the Home. Several of these when admitter were pale, sallow, undeveloped, listless children with no appetite, and yet did not complain of any specific illness. Examinations of feces showed severe, neglected infection in some cases of more than one variety of parasite. They were first given a course of treatment for hookworm and allowed to rest from one to two weeks, when the feces were again examined; if they showed any infection they were given a second treatment. All that had showed signs of infection were re-examined in four weeks, and if necessary, treated again. It is my intention to have these children given a routine examination in six months and to repeat the treatment wherever necessary.

Although I have had these children in charge for over one year, since the eradication of the parasitic infection there has been very little illness at the home. Those who were infected, after treatment took on a different aspect. They lost their sallow complexion, regained appetite and became as other children.

I have made no effort to go into the etiology, symptomatology or treatment for these parasites, but to find out the percentage of children infected and the relative proportion of the different parasites found on routine examination.

It was not surprising to find hookworm to be by far the commonest of the infections, especially in this section, but the large percentage of Hymenolepis nana and Ascaris lumbricoides and the small number of Oxyuris vermicularis was somewhat of a surprise, ${ }^{1}$ as the Oxyuris has been considered quite common, especially by the parents of the patients, while the Hymenolepis nana was considered comparatively rare.

There can be no doubt of the importance of ridding the children of these parasites, as they are undoubtedly a factor in the malnutrition and poor development of many, and may be a predisposing cause of pellagra, tuberculosis, dysentery, subacute and chronic appendicitis and other diseases. In thirty-five cases of pellagra under my care, thirtyone were infected with either hookworm, Hymenolepis, or both.

1. This bears out Schloss in his article in Archives of Pediatrics, February, 1910. 
The frequency of intestinal parasites when looked for, has been shown by other investigators. Still ${ }^{2}$ found 32 parasitic infections in 100 consecutive autopsies. Schloss ${ }^{3}$ found 11 per cent. of the children who came to his dispensary, infected with some variety of parasite. Wilson ${ }^{4}$ reports twenty pinworm infections in 100 consecutive necropsies in children, and other reports bear this out. Although these investigations do not show such to be the case, $\mathrm{McNeil}^{5}$ states that pinworm is comparatively common; that contrary to the general impression, they are usually found in the small intestine, cecum, and appendix, rather than in the lower intestine. In severe infections they may travel down to the anus and be detected there if searched for, but usually they are not found in the stools unless drawn down by an active purge, and even then an active search is necessary. McNeil ${ }^{5}$ also states that it is pretty thoroughly demonstrated that both the pinworm and the whipworm are etiologic factors in attacks of acute and subacute appendicitis, and that they probably lay the foundation for some attacks of suppurative appendicitis.

The reduction of death rate in Bilibid prison from 75 per 1,000 to 9 per 1,000 after quarantining the persons harboring intestinal parasites, seems to indicate that there is some importance to be attached to their presence.

\section{CONCLUSIONS}

1. That parasitic infections in children are far more common than has heretofore been thought.

2. That while hookworm infection is the most often found, Hymenolepis nana and Trichocephalus dispar are by no means rare.

3. That less than 10 per cent. of the cases infected complain of symptoms referable to the infection.

4. That by routine examinations, many cases will be found otherwise unsuspected and by thorough treatment their general condition will be greatly improved.

5. Every county and municipality should appoint a physician for special work along this line, to follow the work done by the Rockefeller Hookworm Commission and under the direction of the state health officer, who should at frequent intervals examine the feces of every child in his district. No child should be permitted to attend a public or private school until after such an examination and the results prove to be negative.

2. Still: Common Diseases and Disorders of Childhood.

3. Schloss: Am. Jour. Med. Sc., 1910, cxxxix, 458.

4. Wilson: Brit Med. Jour., 1913, p. 2676.

5. McNeil: Southern Med. Jour., June, 1915, p. 487. 